\title{
Structural and Compositional Characterization of Suppression of Uniform Ripening in Grapevine: A Paradoxical Ripening Disorder of Grape Berries with No Known Causative Clues
}

\author{
Bhaskar Bondada ${ }^{1}$ \\ Washington State University Tri-Cities, Department of Horticulture, 2710 Crimson Way, Richland, \\ WA 99354
}

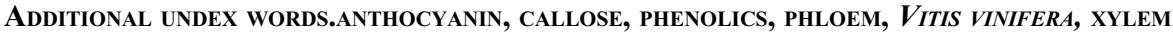

Aвstract. Grapes (Vitis vinifera) have been used as a model system for understanding ripening and ripening-related physiological disorders in fleshy fruit; hence, a comparative analysis was undertaken to explore the mechanistic basis of a paradoxical ripening phenomenon of grape berries known as suppression of uniform ripening (SOUR) shrivel. Fruit organoleptic attributes coupled with morphology and structure, and tissue organization in various organs of healthy and afflicted field-grown grapevines were examined using a range of microscopy techniques. As opposed to healthy berries, SOUR shrivel berries were flaccid and had the lowest $\mathrm{pH}$ and lowest levels of sugars, potassium (K), and malic acid that paralleled with a significant reduction in the synthesis of anthocyanin. On the other hand, titratable acidity, tartaric acids, and tannins were much higher than perfectly healthy berries. The SOUR shrivel cluster tinged its rachis red but held no relationship with flaccidity of the berries because healthy vines totally devoid of SOUR shrivel clusters also displayed same coloration. Furthermore, although the phloem sieve tubes in both cases were plugged with callose, a carbohydrate generally implicated in impeding translocation in phloem, the afflicted grapevines exhibited relatively more plugged sieve tubes. The study revealed that the spatiotemporal configuration of cell and tissue communities determining the structure-function relationship remained intact in afflicted vines throughout the growing season. However, the functionality, especially of flows in phloem sieve tubes, started to decelerate after veraison (initiation of ripening) most likely as a result of early activation of callose synthesis and subsequently plugging of sieve plates during the remaining course of ripening. Hence, in future studies, a broader analysis of phloem sieve tubes entailing its flows and ultrastructure in phloem-girdled grapevines simulating symptoms of SOUR shrivel is needed to characterize the mechanistic basis of SOUR shrivel.
\end{abstract}

Fruit, a major evolutionary acquisition, are designed to execute a plant's evolutionary plan of perpetuating the likeness of species for population persistence, and they do so by functioning as baits to frugivores whose predatory action mediates seed dispersal. This adaptive trait seems to be the underlying selective force in the evolution of fleshy fruit attractive to animals (Rodriguez et al., 2013). Because humans are ancestrally derived from frugivorous primates (Dudley, 2004), these alluring organoleptic and nutritional communicative traits, in effect, intended for reproductive success, also appeal intuitively to their sense of aesthetics and liking, for instance berries of grapevine, grapes as fresh and dry fruit, and wine. Among all the sensorial ripening traits, the total soluble solids (TSS) are the most sought-after attributes as a result of their close relationship with organoleptic quality of fruit. The major components of TSS are soluble sugars, glucose (predominant substrate for fermentation), and fructose and organic acids such as tartaric and malic (Coombe, 1992; Kader, 1999). These compounds vary both spatially and temporally during the normal course of ripening to yield desirable fruit qualities. Because of their organoleptic values, TSS along with flavonoids and volatile aroma compounds

Received for publication 20 May 2014. Accepted for publication 23 June 2014. Financial support for this study was provided by the Wine Advisory Committee, the Washington Wine Commission.

${ }^{1}$ Corresponding author. E-mail: bbondada@wsu.edu. have traditionally functioned as the universal set of criteria for judging fruit for commercial harvesting, especially grapes (Ribéreau-Gayon et al., 2000).

For fruit to attain a morphocompositional aesthetic appeal through cytological and compositional modifications of the parenchymatous tissues for commercial use like in making wine from grapes, it is imperative that fruit undergo unhindered the highly organized events of ripening. Failure to do so results in numerous ripening disorders marked by a wide range of undesirable physical and quality attributes (Watkins, 2007). Some well-known examples of physiological disorders that reduce fresh market quality include blossom end rot of tomato [Solanum lycopersicum (Guichard et al., 2001; Ho et al., 2010)], split and shattered pits and double fruit of peach [Prunus persica (Ceponis et al., 1987)], albino and malformed fruit of strawberry [Fragaria $\times$ ananassa (Singh et al., 2007)], etc. Even the cultivated grapevines, the most ancient and widely known fruit crop of commercial importance (This et al., 2006), develops several physiological disorders. For instance, the bunch stem necrosis, also known as water berry, is the oldest known affliction (Bioletti, 1923). Other ripening physiopathies that render grapes qualitatively incompetent include sunburn, dehydration, and SOUR shrivel (Bondada and Keller, 2012a; Krasnow et al., 2010). Common to all these disorders is shriveling of the pericarp; however, each shrivel type is distinct (Bondada and Keller, 2012a). As yet, there are no known causes for any of these disorders. Among the many 

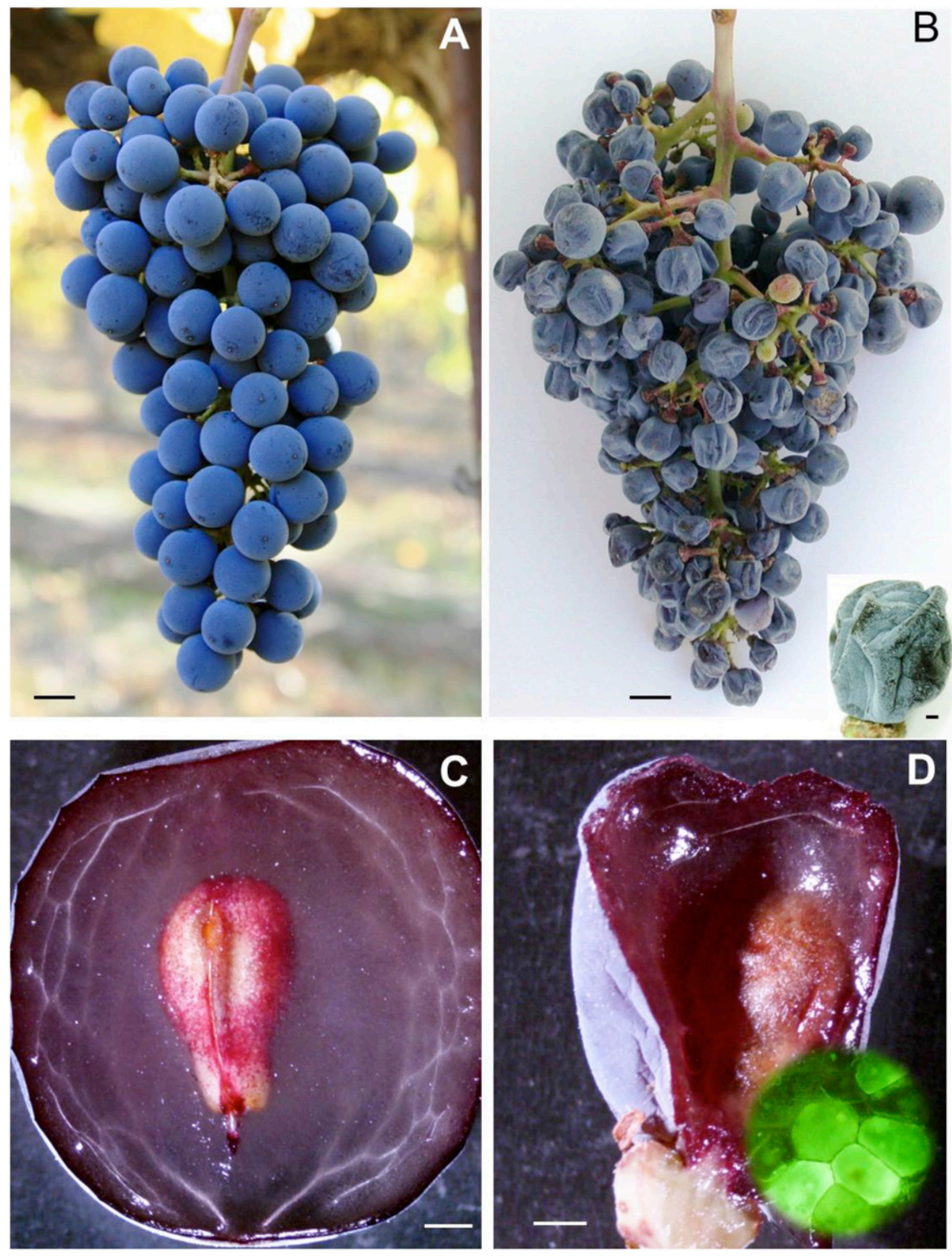

Fig. 1. Photographs of a (A) healthy 'Cabernet Sauvignon' grape cluster showing spherical berries attached to the rachis with healthy pedicels, (B) 'Cabernet Sauvignon' grape cluster wherein the berries are wholly afflicted with suppression of uniform ripening (SOUR) shrivel, but the cluster framework remained healthy (inset, a single SOUR shrivel-afflicted berry resembling a deflated soccer ball), stereomicrographs showing (C) longitudinal section of a healthy berry with a seed overlain by anthocyanins, and (D) longitudinal section of a SOUR shrivel berry with collapsed and nonviable mesocarp that disorganized the vascular bundles but the mesocarp within the vicinity of seeds remained healthy (inset). Scale bars: $10 \mathrm{~mm}(\mathbf{A}-\mathbf{B}), 1 \mathrm{~mm}(\mathbf{B}$ inset), $1 \mathrm{~mm}(\mathbf{C}-\mathbf{D})$.

$2012 \mathrm{~b}$ ) and hybrids (Griesser et al., 2012) worldwide (Bachteler et al., 2013). The key aspect of SOUR shrivel is that it renders afflicted clusters unusable both by humans and the seed dispersers, the avian frugivores, who as humans adopted similar criteria for fruit choice, particularly of preferring hexoses over sucrose (Wilson and Downs, 2012). Typical symptoms of SOUR shrivel include flaccid berries caused by the loss of membrane competence in the mesocarp cells, high osmotic potential resulting from low accumulation of sugars and thus increased sourness, reduced levels of color, amino and oxalic acids, and very often the berries develop an off-flavor (Bondada and Keller, 2012b; Griesser et al., 2012; Knoll et al., 2010; Krasnow et al., 2009). In a given block, yield loss can be up to $50 \%$ (Bondada et al., 2009). What precisely causes such physiological, biochemical, and structural changes are not known. In the context of climate change scenarios (Jones et al., 2010), the incidence of SOUR shrivel is likely to exacerbate in the foreseeable future and with no known clues, the vexation will escalate among grape growers and viticulturists. Consequently, there is an urgent need for preventive measures by exploring its mechanistic basis before it blights the productivity of vineyards around the world.

This article compares the structure and morphology between healthy and afflicted shoots including clusters by using techniques of light and scanning electron microscopy (SEM) concomitant with compositional analysis of fruit to determine whether a functional link exists between vine structure and the incidence of SOUR shrivel. The rationale for such a line of inquiry lay in the fact that success in un-

unexplained shrivel disorders that the grape and wine industry are grappling with today, none is more paradoxical and economically detrimental to fruit quality than SOUR shrivel (Bondada and Keller, 2012a, 2012b), also known as berry shrivel (Hall et al., 2011; Knoll et al., 2010), and sugar accumulation disorder (Krasnow et al., 2009) in viticulture parlance. This physiopathy is relatively a recent and lesser known oddity but has gained much notoriety for being the most perplexing ripening enigma of modern viticulture afflicting both red and white cultivars (Bondada and Keller, derstanding the underlying mechanisms with which they provoke any affliction requires histological analysis, a microscopic tool routinely used in examining physiological disorders of fruit including grapes (Agusti et al., 2001; Freeman, 1976; Miqueloto et al., 2014; Rogiers et al., 2004). This methodology will not only aid in assessing yield and quality losses of SOUR shrivel affliction, but also in providing clues to ripening disorders of other fruit that share analogous symptomatology and eventually in planning preventive measures to curb the overall rising incidence of fruit disorders. 

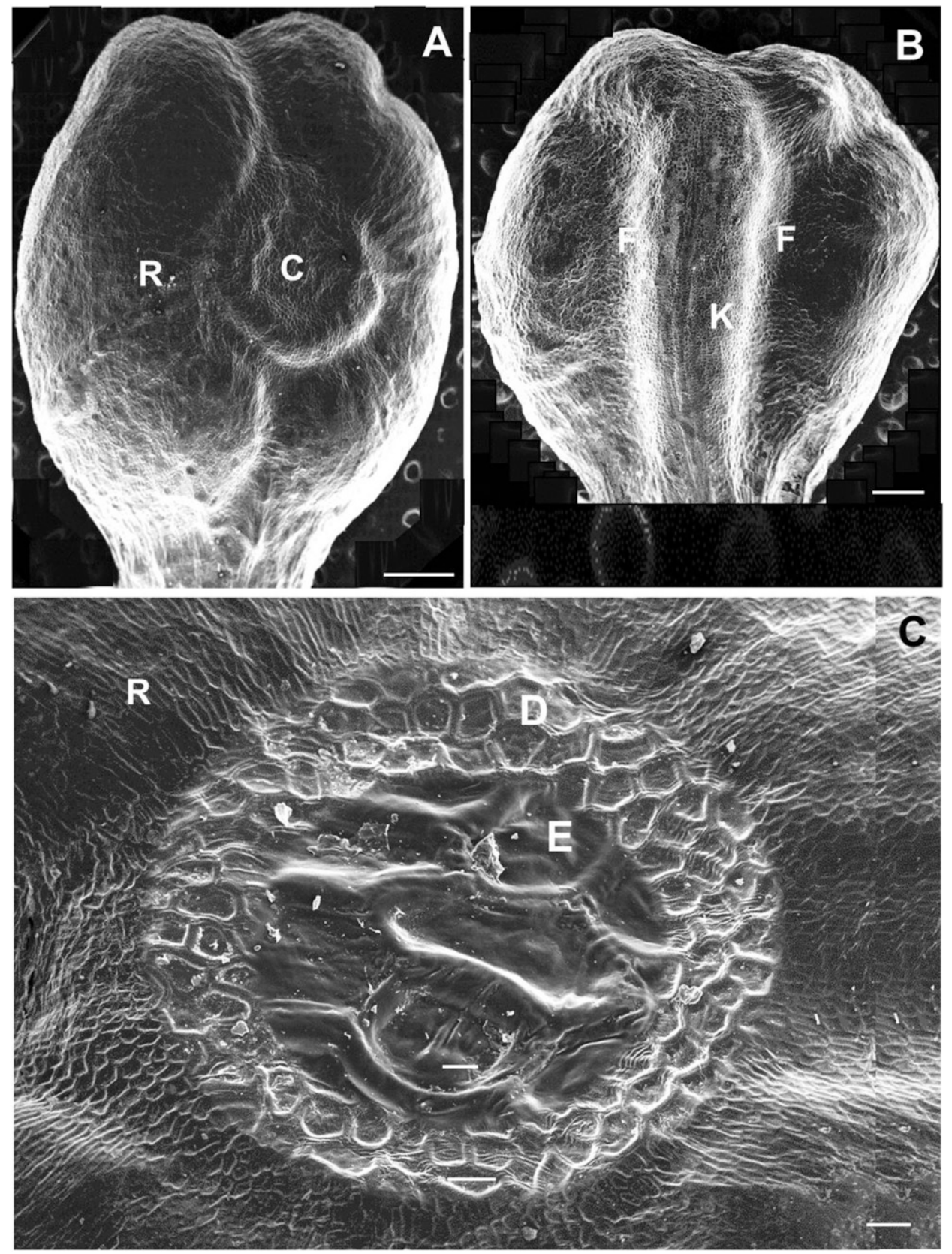

Fig. 2. Scanning electron micrographs of a healthy 'Cabernet Sauvignon' grape seed showing a distinctive chalaza on the (A) dorsal surface and two fossetes (long grooves) on the (B) ventral surface showing a reticulate surface pattern covered with curvilinear, uniform, and smooth anticlinal thick walls; a magnified view of such features is shown in the chalaza (C-E). Scale bars: $500 \mu \mathrm{m}(\mathbf{A}-\mathbf{B}), 50 \mu \mathrm{m}(\mathbf{C}), 100 \mu \mathrm{m}(\mathbf{D}), 50 \mu \mathrm{m}(\mathbf{E}), 10 \mu \mathrm{m} ; \mathrm{C}=$ chalaza; F = fossetes; $\mathrm{K}=$ karina or keel; $\mathrm{L}=$ lenticel; $\mathrm{PF}=$ phloem fiber; $\mathrm{Pi}=$ pith; $\mathrm{R}=$ ruga; $\mathrm{SF}=$ soft phloem; $\mathrm{X}=$ xylem vessels. directions along the cordon (an extension of the trunk) wire from the trunk and were drip-irrigated during the growing season. Training in viticulture parlance refers to the design and development of a grapevine framework. The shoots emerging from the cordon were positioned vertically using catch wires. Vines were spur-pruned during winter; i.e., canes (a mature woody and lignified stem from the previous season's shoot) were cut back to two count nodes/buds (the readily visible buds on a dormant cane, not including the small base buds); the noncount shoots (shoots arising from base buds of the spur) were removed at the beginning of bloom that equated to $\approx 20$ shoots $/ \mathrm{m}$. Throughout the growing season, the vines were continually monitored for the inception of SOUR shrivel disorder, especially during the ripening period. After the appearance of the disorder, the symptomatic vines were identified by tagging the vines and their clusters. Thereafter, the progression of the malady was monitored and finally the symptomatic shoots bearing SOUR shrivel clusters from afflicted grapevines and shoots devoid of SOUR shrivel clusters from perfectly healthy grapevines were sampled for comparing structure and fruit composition.

FruIT COMPOSITIONAL ANALYSIS. Healthy and afflicted clusters from the same vineyard were sampled before harvest, put in a zip-lock bag, and transported to the laboratory. Healthy clusters came from those vine rows that bore absolutely no shriveled clusters. Four replicates of 100 berries from healthy (H) and SOUR shrivel clusters $(\mathrm{n}=$ 80) were removed and de-pediceled using a sharp razor blade. The berries were separated into healthy

\section{Materials and Methods}

Plant material. Commercial vineyards with mature ownrooted V. vinifera cultivars Cabernet Sauvignon and Grenache located near Benton City, WA (lat. $46^{\circ} 15^{\prime} 47.48^{\prime \prime} \mathrm{N}$, long. $119^{\circ} 29^{\prime} 16.09^{\prime \prime}$ W) were chosen for anatomizing SOUR shrivel disorder during the 2011-13 growing seasons. This vineyard was chosen because these vines consistently exhibited incidences of all physiological ripening disorders including SOUR shrivel. The vineyards had vine by row spacing of $1.83 \times 2.74 \mathrm{~m}$ on a uniformly deep (greater than $1 \mathrm{~m}$ ) loamy fine sand. Vines were trained to bilateral cordon, which entailed training the vines in both berries of SOUR shrivel cluster (HBSS), sour-tasting berries of SOUR shrivel cluster (SBSS), and perfectly healthy berries from clusters with no SOUR shrivel $(\mathrm{H})$. All compositional attributes of berries pertaining to soluble solids, glucose + fructose, tartaric and malic acids, $\mathrm{pH}, \mathrm{K}$, total anthocyanins, and tannins were analyzed by a commercial laboratory (ETS Laboratories, Walla Walla, WA).

Microscopy. To examine the structural details of shoots and berries, healthy and afflicted shoots (eight) with clusters were excised from the vines at the end of the season before harvest $(\approx 120 \mathrm{~d}$ after flowering). The stem, rachis, and berries of these shoots were then either cross-sectioned or were 


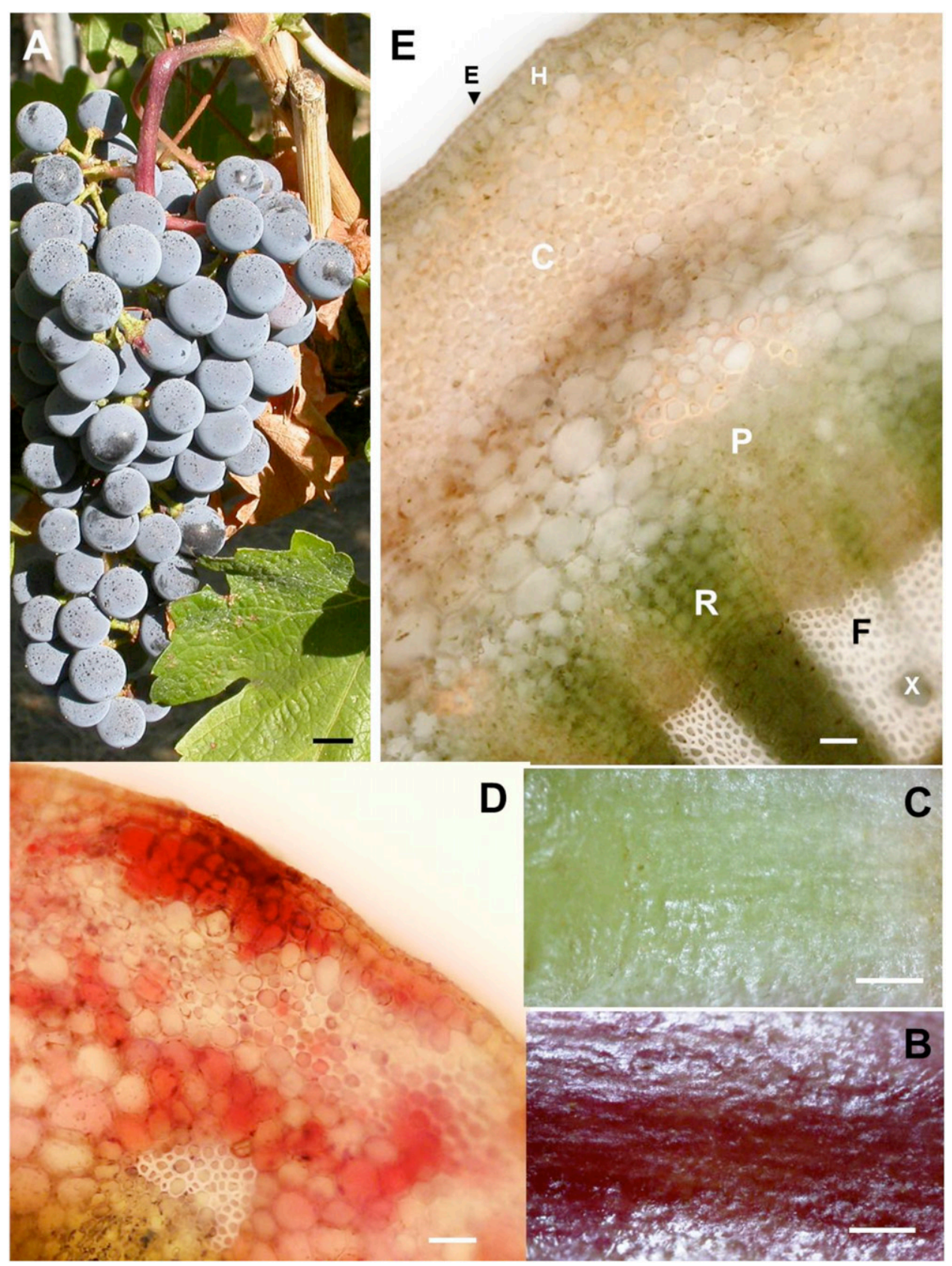

Fig. 3. Photographs of a (A) healthy 'Cabernet Sauvignon' grape cluster with chromated peduncle (hypoclade), (B) a stereomicrograph of chromated peduncle of $\mathbf{A}$ showing anthocyanins on the sun-exposed surface, (C) a stereomicrograph of non-chromated peduncle of A showing colorless cells on the shaded surface, transverse light micrographs of (D) chromated peduncle showing anthocyanin accumulation pattern wherein uniform distribution of anthocyanins occurred in the hypodermal cells with patchy intense clumps in the cortical layers adjoining the hypodermis and the primary phloem fiber cap with less intensity, and (E) shaded peduncle showing no anthocyanin accumulation in any of the tissues. Scale bars: $10 \mathrm{~mm}(\mathbf{A}), 500 \mu \mathrm{m}(\mathbf{B}-\mathbf{C}), 50 \mu \mathrm{m}(\mathbf{D}-\mathbf{E}) ; \mathrm{E}=$ epidermis; C $=$ cortex; $\mathrm{F}=$ xylary fibers $\mathrm{H}=$ hypodermis; $\mathrm{P}=$ phloem $; \mathrm{R}=$ ray parenchyma; $\mathrm{X}=$ xylem vessels.

sectioned longitudinally through the center to examine the cytoarchitectural details using various microscopy techniques.

Light Microscopy. To examine fresh sections, the standard free-hand sectioning technique as described by Bondada (2012) and Ruzin (1999) was used. All sections were cut using a new double-sided razor blade and transferred to a water droplet on a slide and covered with a coverslip. The sections were either viewed with bright field and widefield epifluorescence microscopes (Carl Zeiss, Thornwood, NY) or with a stereomicroscope (Stemi 2000-C; Carl Zeiss) attached with a digital camera (DXM 1200C; Nikon Instruments, Melville, NY), which was used for capturing digital images.

To examine paraffin-embedded tissues, first small tissue samples were cut using a razor blade; subsequently, the tissues were fixed and preserved in formalin-acetic acid-alcohol. The fixed tissues were dehydrated using the tertiary butyl alcohol series, infiltrated and embedded in paraffin, sectioned at $\approx 10 \mu \mathrm{m}$ with a microtome (MT 990; Boeckeler Instruments, Tucson, AZ), affixed to glass slides $(8 \times$ $3 \mathrm{~cm}$ ), and stained with Johansen's safranin $[1 \%(\mathrm{w} / \mathrm{v})$ dissolved in $50 \%$ ethanol] and fast green $[0.2 \%$ $(\mathrm{w} / \mathrm{v})$ dissolved in $95 \%$ ethanol] protocol (Ruzin, 1999). The staining procedure involved rehydration in descending strengths of alcohol, staining with safranin, dehydration in ascending strengths of alcohol, and counterstaining with fast green. When staining was complete, a drop of Permount (Fisher Scientific, Fair Lawn, NJ) mounting medium was used to affix coverslips to the slides. Slides were placed under a compound microscope (Axioskop 2 plus; Carl Zeiss) attached with digital camera (DXM 1200C; Nikon Instruments).

SEM. To observe samples with SEM, the tissues were cut using a razor blade, fixed in 3\% glutaraldehyde overnight, washed with $0.1 \mathrm{M}$ potassium phosphate buffer at $\mathrm{pH} 7.2$, and post-fixed in $2 \%$ osmium tetroxide overnight. Samples were then dehydrated in an ascending series of ethanols ending in $100 \%$ ethanol. The tissue samples were subsequently critical point-dried, coated with gold, and viewed with a SEM (S-570; Hitachi Scientific Instruments, Mountain View, CA) using an accelerated voltage of $15 \mathrm{kV}$. Before using the SEM, the scope magnification was calibrated by photographing a gold grid and compared with a standard. The spot size was set toward the maximum diameter and minimum beam intensity with a standard working distance of $8 \mathrm{~mm}$.

All quantitative data were analyzed by one-way analysis of variance using SPSS 11 (IBM Corp., Armonk, NY). 


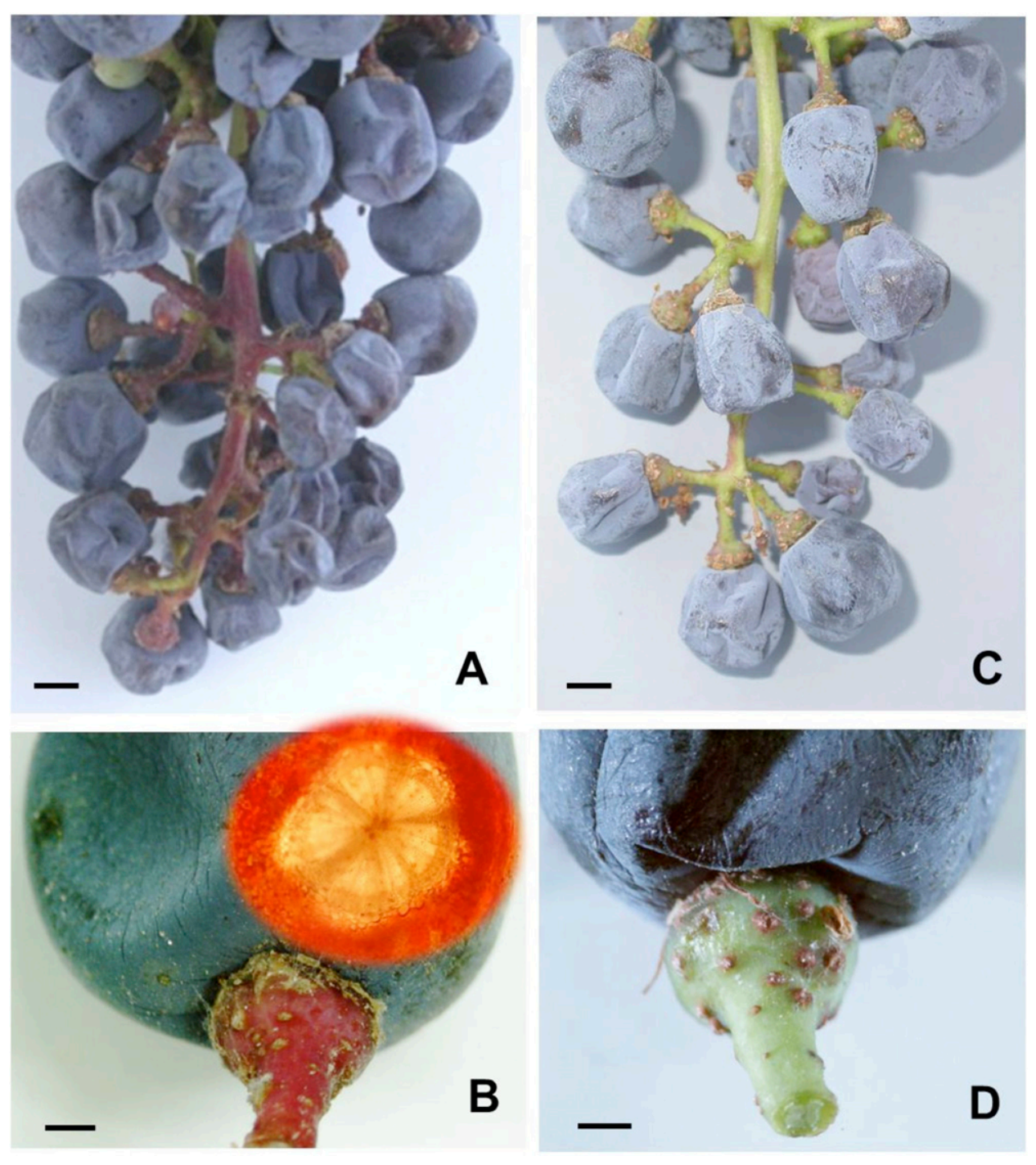

Fig. 4. Photographs of (A) suppression of uniform ripening (SOUR) shrivel 'Cabernet Sauvignon' grape cluster showing chromated rachis, (B) chromated pedicel (inset, transverse light micrograph of pedicel), (C) chlorophyllous rachis and (D) pedicel. Scale bars: $10 \mathrm{~mm}(\mathbf{A}), 1 \mathrm{~mm}(\mathbf{B}), 10 \mathrm{~mm}(\mathbf{C}), 1 \mathrm{~mm}(\mathbf{D})$; E = epidermis; $\mathrm{C}=$ cortex $; \mathrm{F}=$ xylary fibers $\mathrm{H}=$ hypodermis; $\mathrm{P}=$ phloem $; \mathrm{R}=$ ray parenchyma.

\section{Results}

STRuCture of healthy AND AFFlicted vines. In the healthy clusters, the berries with a powdery bloom exterior were spherical and borne on a cluster framework with a proximalto-distal decrease assembly comprising a peduncle (hypoclade) - the stalk of the cluster, rachis - the main framework and axis of the cluster, and pedicels - the stalk of the berries (Fig. 1A). Except for the grotesque physiognomy of the berries reminiscent of a deflated soccer ball, clusters afflicted with SOUR shrivel had an analogous cluster framework (Fig. 1B and inset). The SOUR shrivel berries displayed a distinct wrinkling pattern on the exocarp wherein deep grooves formed into the mesocarp pulling the exocarp away from the receptacle. A longitudinal section of berries revealed a purple-colored exocarp; below it lay a relatively thick and soft translucent mesocarp with colorless juice (Fig. 1C) in the healthy berries. The seeds surrounded by abundant anthocyanins were confined to the locules in the center of the mesocarp (Fig. 1C). The afflicted berries had a collapsed mesocarp, yet the seeds were well developed (Figs. 1D and $2 \mathrm{~A}-\mathrm{E}$ ) and surrounded by live cells in close proximity to the seeds (Fig. 1D inset). SOUR shrivel did not alter the seed morphology and surface ultrastructure. Just like in healthy seeds, the SOUR shrivel seeds had two fossetes (long grooves) on the ventral side and the chalaza (spoonshaped structure) on the dorsal side (Fig. 2A). The seedcoat or testa consisting of two integuments surrounding the embryo and storage tissues, the prime barrier controlling the exchange of water and solutes between the seed and the surrounding soil and a source of seed tannins was intact (Fig. 2C). The most prominent characteristic of the seed surface was polygonal (almost hexagonal) reticulum (network) formed by epidermal cells with thick cell walls (Fig. 2D-E).

The collapsed mesocarp was responsible for the softness and flaccidity of the berries. There was no visible injury to the peduncle or rachis or to the pedicels; however, parts of the cluster framework were chromated involving a radial gradient in pigmentation wherein the more shaded parts of the framework remained green (Figs. 3C and 4CD) and the corresponding surface predominantly red (Figs. 3AB and 4A-B). Transverse sections through the sun-exposed chromated surfaces in healthy and afflicted clusters revealed a colorless single layer of epidermis followed by a ridge of collenchyma cells, cortex, vascular bundles, and central pith (Figs. 3D and 4B). In the pigmented portion of the cluster framework, it mostly accumulated and distributed uniformly in the hypodermal cells; however, patchy intense clumps occurred in the cortical layers adjoining the epidermis and the primary phloem fiber cap, although with less intensity (Fig. 3D). No color accumulation of any pattern occurred on the corresponding shaded green side (Fig. 3E). Except for the pigmented cortical cells, the shaded surface of the inflorescence framework had an identical cellular organization as that of the sun-exposed surface (Fig. 3D-E) in both healthy and afflicted clusters. A similar feature was observed in the pedicel and rachis of both clusters (Fig. 4B). The vascular bundles were collateral and consisted of centripetally directed xylem and centrifugally directed phloem capped by a ridge of sclerenchymatous fibers were arranged as a pie-shaped sectors separated by rays (Fig. 5A-B). The secondary xylem vessels in healthy as well as afflicted clusters did not occur in uniform files but rather were clustered close to the pith and cambium and were larger than the rest of the vessels in peduncles with 


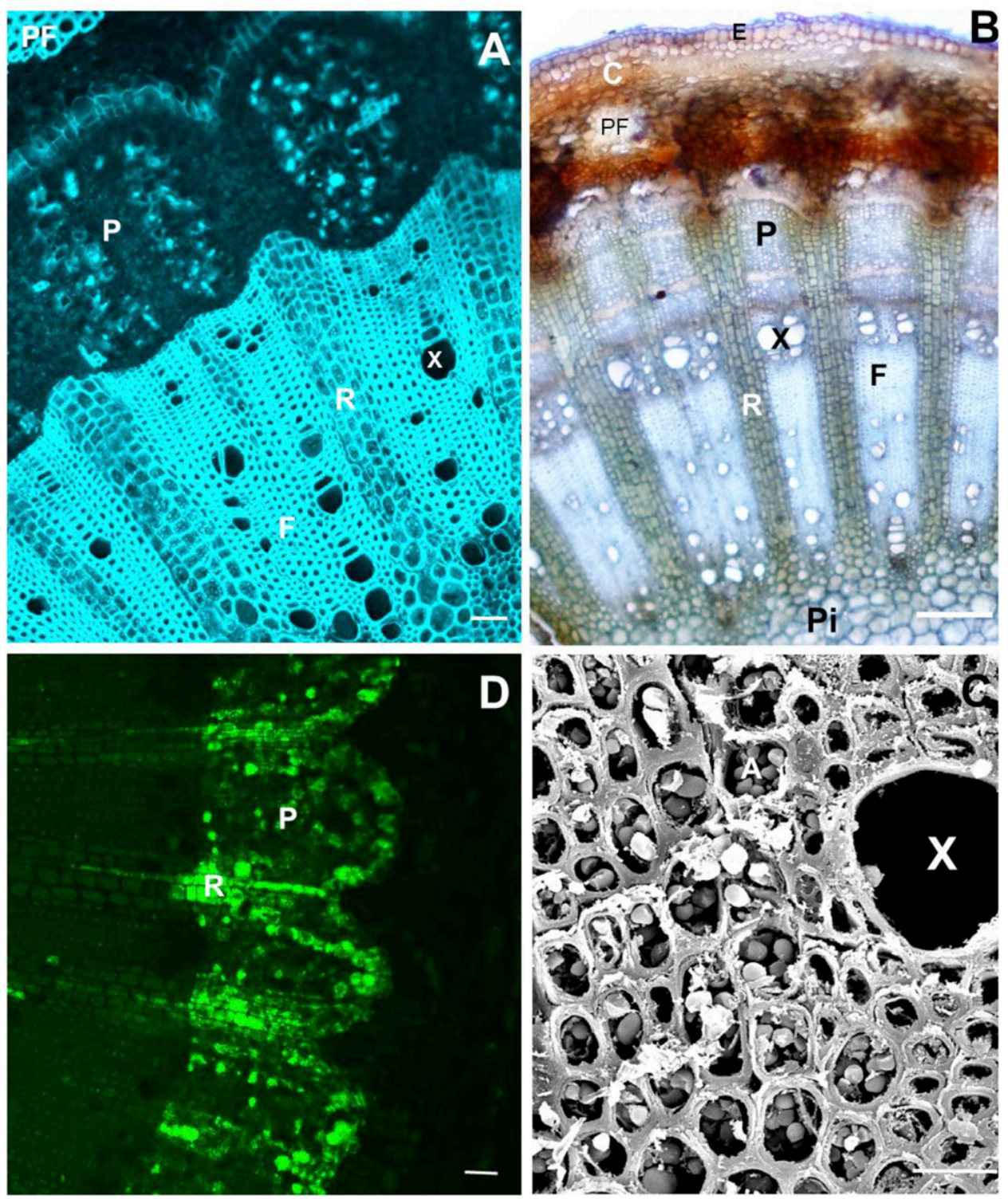

Fig. 5. Radial vascular tissue patterns in vascular bundles of the stem wherein the xylem and phloem are arranged in a specific radial pattern. Transverse light micrographs of a (A) healthy 'Cabernet Sauvignon' peduncle showing secondary growth arising from collateral vascular bundles but no periderm formation, (B) suppression of uniform ripening (SOUR) shrivel 'Cabernet Sauvignon' grape peduncle showing both secondary growth and periderm formation; the phloem is located toward the abaxial side (outside) and the xylem is located toward the adaxial side (inside) and forms a ring-like pattern around a parenchymatous pith cells; (C) confocal laser scanning microscopy (CLSM) image of SOUR shrivel 'Cabernet Sauvignon' peduncle showing viable cells of the phloem and parenchyma cells, and (D) scanning electron micrograph of a healthy 'Cabernet Sauvignon' peduncle xylem parenchyma cells showing abundant amyloplasts. Scale bars: $100 \mu \mathrm{m}(\mathbf{A}), 200 \mu \mathrm{m}(\mathbf{B}), 50 \mu \mathrm{m}$ (C), $20 \mu \mathrm{m},(\mathbf{D}) ; \mathrm{A}=$ amyloplasts; $\mathrm{E}=$ epidermis; $\mathrm{C}=$ cortex; $\mathrm{F}=$ xylary fibers; $\mathrm{H}=$ hypodermis; $\mathrm{PF}=$ primary phloem fiber; $\mathrm{P}=$ secondary phloem; $\mathrm{R}=$ ray parenchyma; $\mathrm{X}=$ xylem vessels

a brownish bark comprising dead epidermis, cortex, and part of the primary phloem (Fig. 5B). On the other hand, in the chlorophyllous peduncles of healthy and afflicted clusters, most of their solitary xylem vessels were distributed toward the pith (Figs. 5A and 6A). The xylem parenchyma cells of the peduncle showed plenty of amyloplasts (Figs. 5C and 6B) in both types of clusters. The vessels existed as files of open interconnected vessel elements with simple perforation plates, the junctions between single-celled vessel elements; i.e., the adjoining end walls completely broken down as the cells matured forming a single opening (Figs. 7 and 8A) and on the interior surface, the secondary cell wall occurred as a helical thickening (Fig. 8B) or as biseriate scalariform pits, which are not perforations but areas in which there is no secondary cell wall (Fig. 8C). Phloem tissue consisted of sieve tube members, companion cells, parenchyma cells, and fiber cells (Figs. 5A-B and 5D), which lay below the cortex and periderm in the chlorophyllous (Fig. 5A) and brownish (Fig. 5B) peduncles, respectively. In both peduncle types, the vascular tissues consisted of abaxial (centrifugal) secondary phloem and adaxial (centripetal) secondary xylem (Figs. 5A-B and 5D). In this architecture, the phloem was composed of rays that occurred in alternate radial blocks and two types of tissues that occurred as alternate tangential bands, a hard phloem band consisted of fibers that provide structural support, and a soft phloem band consisted of sieve tubes (Figs. 5B-D), which perform the actual transport of the phloem sap. The hard phloem band was narrow and dense, whereas the soft phloem band was wider with relatively large cells (Fig. 5B). The phloem was subepidermally capped by a ridge of fiber cells (Fig. 5B). The sieve tube members were connected end to end at sieve plates forming a sieve tube and side by side at the sieve (Fig. 9A). Sieve elements were not cylindrical, but rather were bone-shaped and tapered toward their center with the largest diameters found at the sieve plates (Fig. 9B). The pore size in the sieve plates was relatively the same (Fig. 9B inset). In both cases, sieve plates were porous with a relatively same pore size but were heavily deposited with callose as revealed by staining it with aniline blue and observing fluorescence with ultraviolet fluorescence microscopy (Fig. 9).

Except for the cell size differences, the cellular organization of canes was similar to the anatomy of the inflorescence framework in afflicted as well as healthy vines. In both cases, canes exhibited a highly structurally specialized vascular system marked by possession of secondary phloem tissues, vascular wide rays, large xylem conduits juxtaposed with mechanically robust fiber cells, and periderm outside the phloem (Fig. 10A). Among the vascular tissues, xylem vessels were the largest visible structures with thick walls, which were 


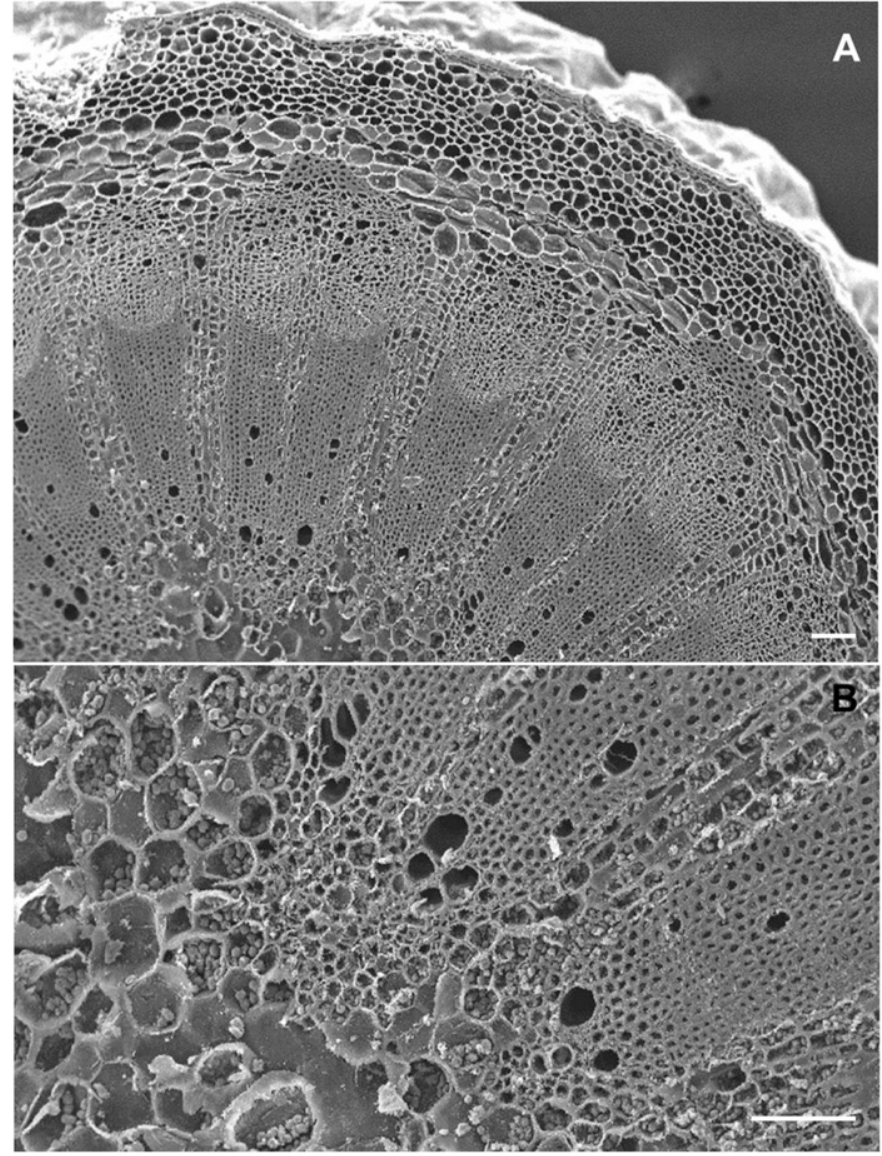

Fig. 6. Scanning electron micrographs of (A) a healthy chlorophyllous 'Cabernet Sauvignon' grape peduncle of secondary growth showing cellular organization typical of canes and (B) high magnification of $\mathbf{A}$ showing abundant amyloplasts in the parenchyma cells. Scale bars: $100 \mu \mathrm{m}(\mathbf{A}-\mathbf{B})$.

diffuse in distribution (Fig. 10B), but the vascular rays dominated the cross-sections. Most lumens of solitary vessels were circular to elliptical in shape (Fig. 10B), whereas the lumens of radial multiples were neither circular nor elliptical as a result of linear union of their common walls (Fig. 10B inset). Akin to peduncles, the xylem parenchyma cells showed an abundance of starch as amyloplasts (Fig. 10C). The xylem vessels were interrupted by tilted simple perforation plates with double rims (Fig. 10D-E). The intervessel pit membranes as observed with SEM were intact (Fig. 10F). The secondary phloem was composed of rays that occurred in alternate radial blocks and two types of tissues that occurred as alternate tangential bands, a narrow and dense hard phloem band consisted of fibers and a wider soft phloem band consisted of sieve tubes (Fig. 10A). The primary phloem was subepidermally capped by a ridge of fiber cells (Fig. 10A). As opposed to inflorescence, the layered configuration of phloem tissues consisting of alternating bands of hard phloem and soft phloem was easily distinguishable in canes.

Fruit composition. Because the anatomical and functional architecture of organs determines fruit quality attributes, fruit composition was compared between healthy and afflicted clusters to delineate the mechanistic basis of SOUR shrivel. The healthy berries showed typical composition that is commonly observed at commercial harvest (Tables 1 and 2). On the

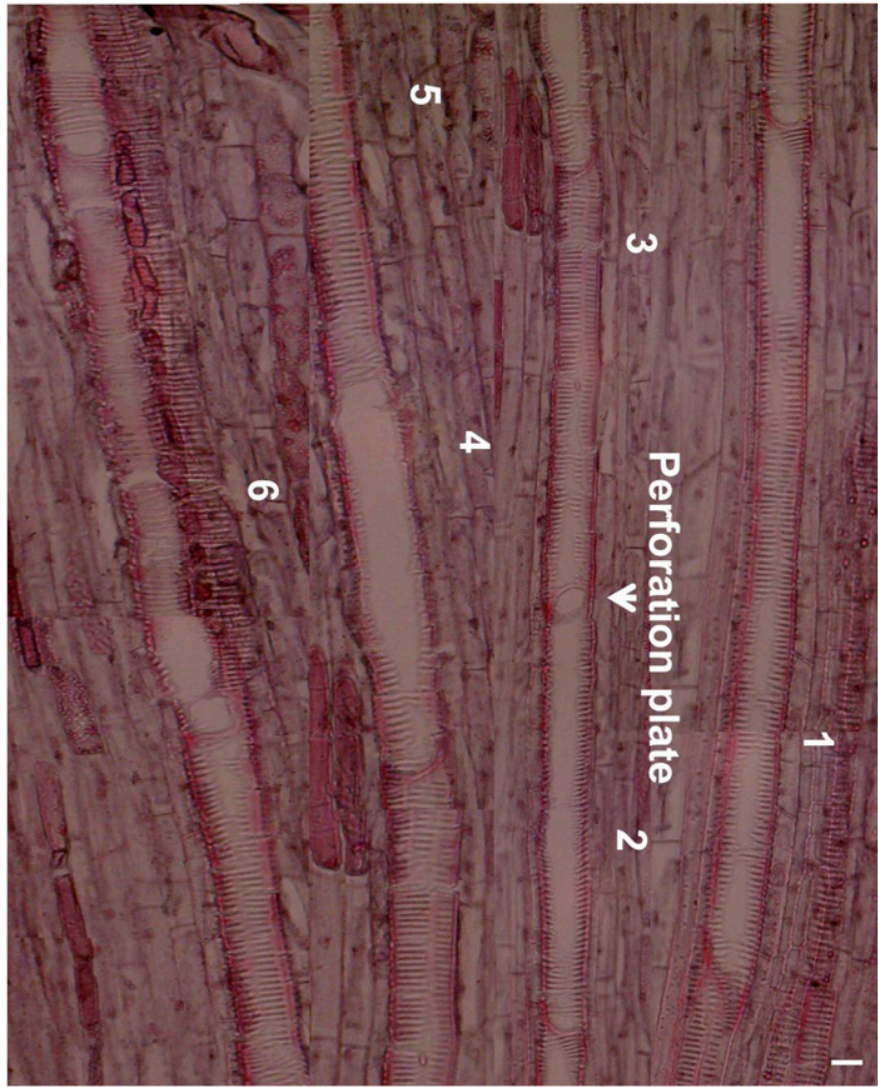

Fig. 7. Longitudinal radial section of 'Cabernet Sauvignon' grape rachis showing a file of open interconnected xylem vessels (protoxylem) in which the primary and secondary cell wall of the end wall is perforated with a single hole, a pattern called simple perforation plate, and closely spaced helical secondary cell wall thickenings in suppression of uniform ripening (SOUR) shrivel rachis. Perforation plates, be it simple or complex (e.g., scalariform plate), are controlled by the patterned deposition of secondary wall on both ends of vessel elements. Scale bars: $10 \mu \mathrm{m}$.

contrary, in the afflicted clusters, two types of berries differing in fruit composition were identified (Tables 1 and 2). HBSS berries appeared healthy with no apparent shriveling of the pericarp, but their composition was compromised. SBSS berries had collapsed mesocarp and a dramatic reduction in all desirable fruit quality attributes that are normally sought after at harvest (Tables 1 and 2). For instance, the SBSS berries had the lowest sugar accumulation that paralleled with a significant reduction in the synthesis of anthocyanin (Tables 1 and 2). The same was true for the amounts of $\mathrm{K}$ and malic acids and $\mathrm{pH}$. On the other hand, titratable acidity, tartaric acids, and tannins were much higher than HBSS and perfectly healthy $(\mathrm{H})$ berries. The composition of HBSS berries rather than being intermediate between healthy and SOUR shrivel berries tended to resemble those of healthy berries (Tables 1 and 2).

\section{Discussion}

ANALYSIS OF ANATOMICAL AND FUNCTIONAL ARCHITECTURE OF THE GRAPEVINE. Although analyses of fruit ripening over the past few years yielded new insights into ripening, there is still much that remains to be learned about fruit development and ripening (Giovannoni, 2007). In the wake of such inadequacy, not only does it become difficult to put an accurate interpretation 




Fig. 8. A file of (A) open interconnected xylem vessels with simple perforation plate in suppression of uniform ripening (SOUR) shrivel 'Cabernet Sauvignon' rachis, (B) fluorescent segregated network of xylem vessels with helical secondary wall thickenings in SOUR shrivel 'Cabernet Sauvignon' rachis, (C) xylem vessels with scalariform pitting from SOUR shrivel 'Cabernet Sauvignon' rachis. Scale bars: $50 \mu \mathrm{m}(\mathbf{A}-\mathbf{B}), 25 \mu \mathrm{m}(\mathbf{C})$.

corroborate to its post-veraison inception. This type of architecture arises either from competition among developing flowers and fruit for resources (Diggle, 1995) or redistribution of its own assimilates to other plant organs (Vaillant-Gaveau et al., 2011). However, what was perplexing was that in such a cluster framework, the maturing berries, instead of culminating into a fleshy indehiscent pericarp protecting a soft placenta, shriveled as a result of collapsed mesocarp (Fig. 1D) as the ripening progressed. This was somewhat puzzling because fruit generally dehydrate in vivo and subsequently shrivel distinctively with no apparent injury to the framework only late in the ripening period (Bondada and Keller, 2012b; Tilbrook and Tyerman, 2008). Conversely, SOUR shrivel develops any time after the berries have been initiated into veraison (Bondada and Keller, 2012a; Krasnow et al., 2009), and akin to late-season dehydrated berries, it also occurs on an intact cluster framework (Bondada and Keller, 2012b; Hall et al., 2011; Knoll et al., 2010). However, in the case of SOUR shrivel, chromation (Figs. 3 and 4) in addition to intactness of the framework was observed and the obvious explanation for such phenomenon was accumulation of anthocyanins in its exterior tissues (Figs. 3 and 4). Although a similar chromation pattern was observed in perfectly healthy cluster frameworks, they bore no SOUR shrivel berries (Fig. 3A) ruling out any link between SOUR shrivel incidence and chromation of the cluster framework as suggested in previous studies (e.g., Bondada et al., 2009). In a comparative context, Nozzolilo (1979) concluded that the presence of anthocyanins did not cause shorter stem length in

on its mechanics, especially when the anomaly is unfamiliar to us, but it is also not knowing its mechanistic basis compounds production problems of which most belong to yet-to-be resolved ripening disorders (Bondada and Keller, 2012a, 2012b). Nonetheless, as far as SOUR shrivel is concerned, one aspect is certain that it initiates after veraison (French word and in viticulture parlance denotes the onset of ripening) (Bondada and Keller, 2012a, 2012b; Krasnow et al., 2009). The conical clusters (Fig. 1A-B) and well-developed integuments of pyriform seeds comprising dry tissues (Fig. 2) as typically observed in commercial cultivars at harvest (Bondada and Keller, 2012b) for protection and seed dispersal strongly pea seedlings. So, what is the rationale for this spatially regulated transcriptional activation of anthocyanin biosynthesis genes in the cluster framework? The logical explanation is that because all anthocyanic frameworks originated from the west aspect of the canopy where sunlight is always intense in the afternoon in north-south-oriented rows, light irradiation acted as a trigger for the synthesis of anthocyanins. Such photoinduction of anthocyanin accumulation most plausibly resulting from tissue-specific expression of $V v m y b A 1$, a $M y b$-like transcriptional activator gene for anthocyanin synthesis (Jeong et al., 2006) through cytoplasmic anthocyanidin synthase (Wang et al., 2011) in otherwise chlorophyllous rachis, is an 


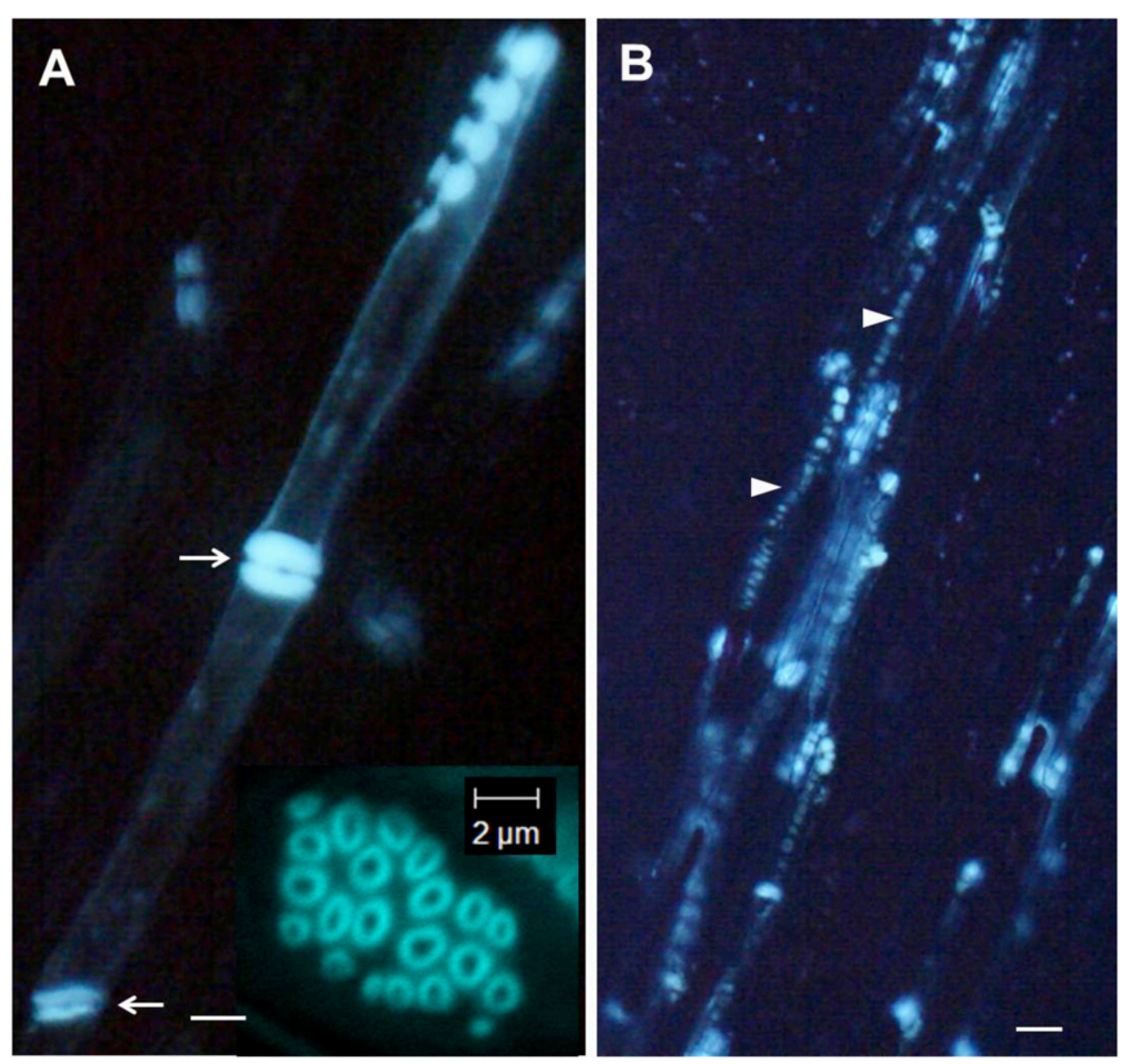

Fig. 9. Longitudinal light micrographs of a healthy 'Cabernet Sauvignon' grape peduncle showing phloem sieve tubes with a plentiful deposition of callose as bright fluorescence arising from its characteristic reaction with aniline blue fluorochrome, an indicator of callose, on (A) sieve plates (arrows) and (B) lateral sieve areas in the side walls (longitudinal walls) (arrowheads) as revealed by an epifluorescence microscope. (Inset) Simple transverse sieve plate. Scale bars: $20 \mu \mathrm{m}(\mathbf{A}-\mathbf{B})$.

adaptation to prevent or offset photo-oxidative damage by providing a light-absorbing screen for photosynthetic cells. This preventive action is similar to what leaves (Harris et al., 2013; Liakopoulos et al., 2006) and other plant organs of many species do either transiently or permanently in or just below the epidermis including mesophyll cells (Hughes, 2011; LevYadun et al., 2002). Another important feature associated with SOUR shrivel, which was also observed in healthy clusters, was browning of their peduncles (Fig. 5A). This commonality strongly suggests that such morphological transformation is a normal feature, which takes place when green stems undergo periderm formation (Stevenson et al., 2005) after secondary growth (Bondada, 2012) and therefore has no causal connection between browning and SOUR shrivel.

Unlike the peduncle, the rachis and the secondary and tertiary branches hardly ever form periderm but will undergo secondary growth to form radial sectors of centripetal xylem and centrifugal phloem bordered by xylem ray parenchyma cells as the radius (Figs. 5, 6, and 10). This was observed in both cases (healthy and afflicted vines) wherein the xylem vessels with large lumen developed spiral and pitted secondary cell wall thickenings with simple perforation plates (Figs. 7 and 10). These are common characteristics of grapevine (Chatelet et al., 2006), which based on the model species, Arabidopsis thaliana is probably formed by ectopic expression of VND7 (VASCULARRELATED NAC-DOMAIN7) and VND6 genes (Oda and Fukuda, 2012). The spiral pattern was homogenously distributed in the longitudinal series of vessel elements (Figs. 7 and 8A) as opposed to combinations of annular, helical, or reticulate types that occur in a similar series, and sometimes even in a given element, but their origin, distribution, and role are mostly unknown (Esau, 1965). Whereas the spiral sculpturing evolved for longitudinal extension while transporting water efficiently to growing areas (Carlquist, 1975), the presence of simple perforation plates in grapevines reflects an exposure to seasonal dry conditions during its evolutionary history. This explains grapevines' relative tolerance to dry and/or warm climates, the most common habitat of commercial viticulture. An important point to remember here is that these simple plates are not meant for survival through dry periods, but rather for conducting water rapidly when it becomes available after a dry period (Carlquist, 1975). Unlike in canes and inflorescence framework, grapevine leaf veins possess scalariform perforation plate (Bondada, 2012) emphasizing dependence of plate sculpturing on vessel diameter. In view of the efficient water conduction system of grapevines (Figs. 7, 8, and 10) and the fact that SOUR shrivel initiates after veraison (Bondada and Keller, 2012a, 2012b), there is a little likelihood of water stress triggering SOUR shrivel.

Both healthy canes and canes that bore SOUR shrivel exhibited vascular features typical of lianescent taxa, i.e., large xylem conduits dominated by vascular rays (Fig. 10). Such a sectored vascular architecture is an evolutionary adaptation for high stem flexibility while maintaining or increasing hydraulic conductivity in their natural habitat (Carlquist, 1991). It is noteworthy that some xylem vessels in the radial sectors occurred as radial multiples (Figs. 10A-B), which was expected to be either in healthy or afflicted vines, but not in both vines given that the intent of this study was to find a causal link between structural disparities and SOUR shrivel. Even their presence in grapevines was a bit puzzling until recently (Brodersen et al., 2013) because these have been prominently reported in Anemopsis californica (Carlquist, 1984). These multiples, also known as xylem conductive vessel relays conjoin large conduit vessels through scalariform pitting within a xylem sector that would otherwise remain isolated (Brodersen et al., 2013). In addition, they provide a safe water conductive system in the event the wide vessels got cavitated as a result of stress conditions (Carlquist, 1984; Zimmermann, 1978). 


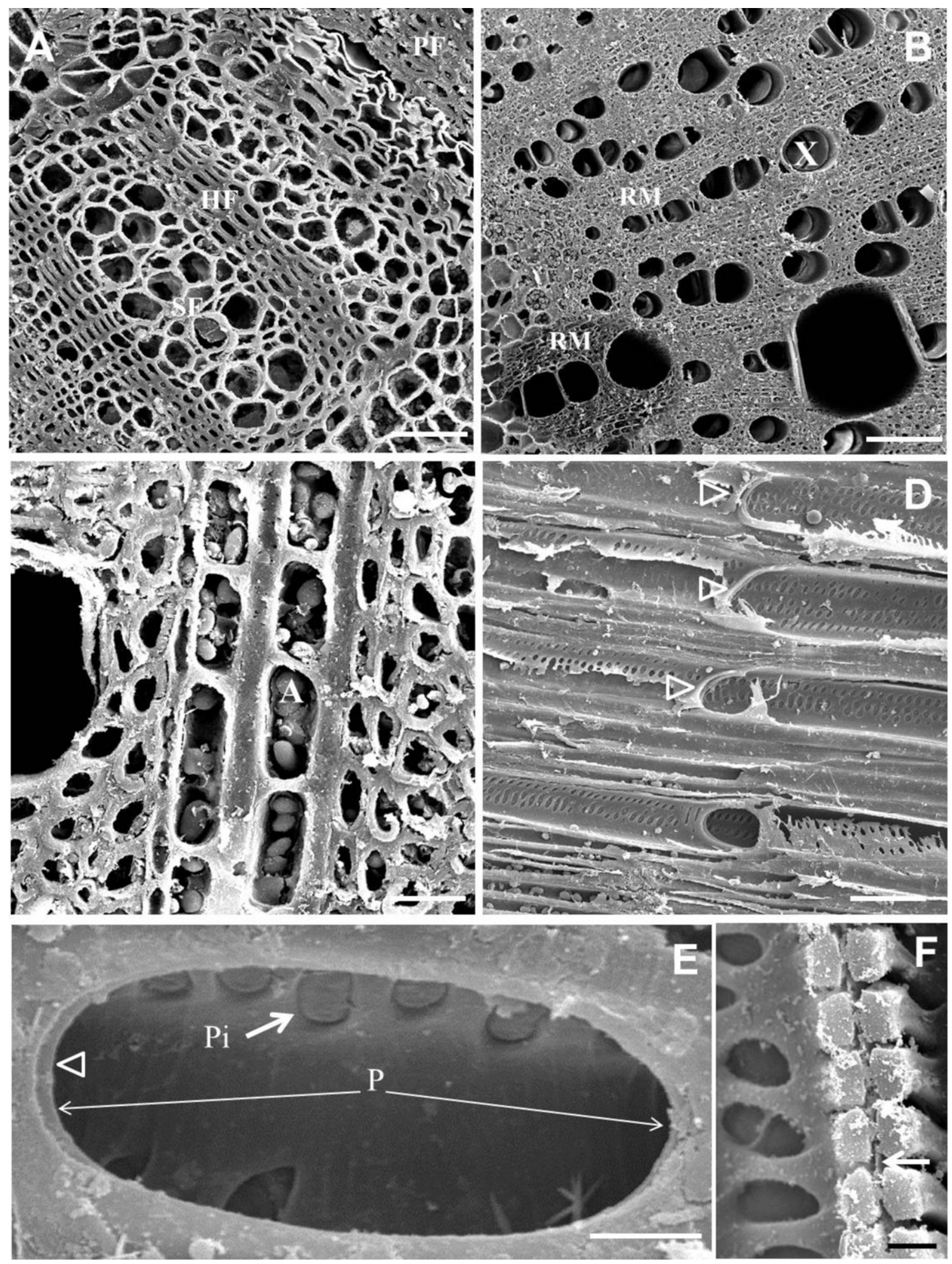

Fig. 10. Scanning electron micrographs of a cane transverse section of (A) healthy 'Cabernet Sauvignon' cane showing hard and soft bands of secondary phloem, (B) diffuse porous xylem vessels; xylem vessels mostly solitary and frequently slightly elliptical in cross section were diffuse in distribution, (left inset) radial multiples of xylem vessels, (right inset) a vessel pair from left inset showing (intervessel) vessel-to-vessel pit area, (C) a ray xylem parenchyma cell showing circular to elliptical amyloplasts, (D) xylem vessels with simple tilted (arrowhead) perforation plates wherein part of it was cut away during sectioning leaving behind arcs (collar) of secondary cell wall material, (E) double rims of an elliptical simple perforation plate (face view) bounded by the secondary cell wall thickenings arranged obliquely on the end wall from healthy vine; lateral wall nonporose pits have intact smooth pit membranes (which is the modified primary cell wall and middle lamella of the adjacent vessel elements) that covers the pit aperture (darker area), the circular area is the pit boundary, and (F) a section of intervessel wall i.e., pit membrane in pit pairs in a side wall showing the structure of individual pits; intervessel pit membranes (arrow) remain intact. Scale bars: $100 \mu \mathrm{m}(\mathbf{A}-\mathbf{C}), 50 \mu \mathrm{m}(\mathbf{D}), 10 \mu \mathrm{m}(\mathbf{E}), 5 \mu \mathrm{m}(\mathbf{F}) ; \mathrm{A}=$ amyloplast; $\mathrm{HF}=$ hard phloem; $\mathrm{PF}=$ primary phloem fiber cap; $\mathrm{P}=$ perforation (open area); $\mathrm{Pi}=$ pit; $\mathrm{SF}=$ soft phloem; $\mathrm{X}=$ xylem vessels 
Table 1. Fruit composition of healthy and suppression of uniform ripening (SOUR) shrivel-afflicted berries of the grapevine cultivar Grenache ( $\mathrm{n}=80$ clusters).

\begin{tabular}{|c|c|c|c|c|c|}
\hline Berry type ${ }^{z}$ & Sugar (mg/berry) & Glu+Fru (mg/berry) & TA $\left(g \cdot L^{-1}\right)^{y}$ & $\mathrm{pH}$ & $\mathrm{K}$ (mg/berry) \\
\hline$\overline{\mathrm{H}}$ & $370 c^{x}$ & $333 \mathrm{c}$ & $4.4 \mathrm{~b}$ & $3.60 \mathrm{~b}$ & $2.05 \mathrm{c}$ \\
\hline SBSS & $290 \mathrm{a}$ & $261 \mathrm{a}$ & $6.7 \mathrm{a}$ & $3.33 \mathrm{a}$ & $1.73 \mathrm{a}$ \\
\hline
\end{tabular}

${ }^{\mathrm{z}} \mathrm{H}=$ healthy berries from healthy cluster; HBSS = healthy berries from SOUR shrivel cluster; SBSS = sour-tasting berries from SOUR shrivel cluster.

${ }^{\mathrm{y}}$ Glu+Fru $=$ glucose + fructose; $\mathrm{TA}=$ titratable acidity.

${ }^{\mathrm{x}}$ Means within a column followed by the same letter are not significantly different by Holm-Sidak test at $P<0.05$.

Table 2. Fruit composition of healthy and suppression of uniform ripening (SOUR) shrivel-afflicted berries of the grapevine cultivar Grenache $(\mathrm{n}=80$ clusters).

\begin{tabular}{lcccc}
\hline Berry type $^{\mathrm{z}}$ & Malic acid (mg/berry) & Tartaric acid (mg/berry) & Tannins (mg/berry) & Total anthocyanins (mg/berry) \\
\hline H & $1.32 \mathrm{c}^{\mathrm{y}}$ & $8.81 \mathrm{~b}$ & $0.49 \mathrm{~b}$ & $0.94 \mathrm{c}$ \\
HBSS & $1.04 \mathrm{~b}$ & $9.30 \mathrm{~b}$ & $0.42 \mathrm{a}$ & $0.74 \mathrm{~b}$ \\
SBSS & $0.24 \mathrm{a}$ & $12.9 \mathrm{a}$ & $0.55 \mathrm{c}$ & $0.69 \mathrm{a}$
\end{tabular}

${ }^{\mathrm{z}} \mathrm{H}=$ healthy berries from healthy cluster; HBSS = healthy berries from SOUR shrivel cluster; SBSS = sour-tasting berries from SOUR shrivel cluster.

${ }^{\mathrm{y}}$ Means within a column followed by the same letter are not significantly different by Holm-Sidak test at $P<0.05$.

Evidently, vessel grouping in grapevines is a consequence of normal cambial activity (Brodersen et al., 2013) and the fact that they were observed in both cases rules out them having any bearing on the incidence of SOUR shrivel. Unlike the xylem vessels, the xylem parenchyma cells lacked well-defined secondary cell walls in both cases (Figs. 5 and 10). Because these cells function in storage and lignification (Bondada, 2012; Stevenson et al., 2005), both vines showed an abundance of starch as amyloplasts (Figs. 5C and 10C) and lignification of secondary cell walls in vessel elements as well as fibers. Intervessel pit membranes, the remnants of the primary cell walls and middle lamellae (Carlquist, 2001), were intact in both cases, which is typical in Vitis species limiting the movement of air and pathogens between connected vessels while maintaining water transport (Choat et al., 2008; Sperry and Hacke, 2004). However, it is possible for them to become structurally weaker and more easily degraded if vines became infected with pierce's disease [Xylella fastidiosa (Sun et al., 2011)].

The SOUR shrivel berries collapsed, which generally occurs when cells lose their viability (Bondada and Keller, 2012a, 2012b; Tilbrook and Tyerman, 2008) with shriveling increasing with a decrease in viable cells (Bonada et al., 2013; Bondada and Keller, 2012a, 2012b). Although, in a given cluster, all berries are susceptible to shrivel regardless of their position, it is the distal berries that generally shrivel (Fig. 1B) because they develop with positional and architectural challenges causing a reduction in their sink size and sink activity and eventually ripening either as a result of sluggish vascular flows or resource limitation imposed by the high sink activity of proximal berries. Furthermore, because grapevines produce inflorescence primordia in the previous growing season before going into dormancy (Pratt, 1971), there may be pre-existing constraints on the development of distal fruit. For instance, fruit development could be limited by unequal formation of meristems along plant axes as it happens in mayapple [Podophyllum peltatum (Jones and Watson, 2001)]. This reproductive strategy involving gentle pruning action, i.e., berry thinning of distal berries, is perhaps an evolutionary compromise to ensure successful continuation to the next generation by enhancing the size and quality of proximal berries at the expense of distal berries. Despite the collapse of the mesocarp, cells in the vicinity of seeds were alive (Figs. 1D inset) indicating that cell death proceeded in an out-to-in progression; hence, seeds neither have a role in inducing cell death nor in expanding volume. This means berry expansion occurs through a physical process involving phloem influx of water, which was obviously limited in SOUR shrivel berries. On the contrary, seeds of lateseason dehydrated berries have been implicated in inducing cell death when it initiated near the locular region (Fuentes et al., 2010). However, the seeds (Figs. 1D and 2) themselves regardless of the type of shrivels (Bondada and Keller, 2012a) are unaffected; the same is true for the epicuticular wax (Bondada and Keller, 2012b) reinforcing the fact that SOUR shrivel initiates after veraison.

Now the logical question to propose is what makes SOUR shrivel berries lose their cell viability and the obvious process that can trigger such an event is programmed cell death (PCD), an evolutionarily conserved controlled-death program involving collapsing of vacuoles (Fukuda, 2000). PCD is an essential component of plant responses to biotic and abiotic stresses (Greenberg, 1996; Hara-Nishimura and Hatsugai, 2011) and also an integral part of plant development; for instance, it occurs in the mesocarp of most fruit including grape late in development (Bouzayen et al., 2010; Krasnow et al., 2008; Tilbrook and Tyerman, 2008) and in fruit that experience unfavorable ripening conditions (e.g., Bondada and Keller, $2012 b$ ). So, the early activation of cell death in SOUR shrivel berries is indicative of afflicted grapevines deploying PCD as a defense mechanism against abiotic stress. The other mechanism is to turn off sugar transporters in berries, which could arise from interruptions in the metabolic process in response to abiotic cues, lose physiological function, and then enter stages of PCD. Plants perform such degenerative action to protect themselves against the process of whole plant death called monocarpic senescence, which sometimes occurs after fertilization (Greenberg, 1996). It may also result indirectly as a 
non-physiological cell death after the loss of their supply of nutrients and sugars as a result of inactivation of the phloem pathway ensuing from plugging of sieve plates (Fig. 9). So, from a plant's perspective, grapevines that develop SOUR shrivel are onto a good thing. The abiotic factors that have been proposed to correlate with the incidences of SOUR shrivel include soil, nutritional, and environmental conditions including viticultural practices (Bondada et al., 2009).

In both cases, bone-shaped phloem sieve tube elements with porous thick sieve plates existed, an architectural assembly that allows for rapid translocation of sucrose (Knoblauch and Peters, 2010). This signifies that conduits appropriate to translocating sugars into fruit of SOUR shrivel clusters existed until the end of the season; hence, a possible link between sieve tube geometry and the incidence of SOUR shrivel is very unlikely. The likely scenario for inducing SOUR shrivel would be if the pores in sieve plates were occluded because they permit uniform flow in the sieve tubes. In both healthy and afflicted vines, accumulation of callose was detected in the sieve plates, the prime target for flow blockage (Fig. 9). Then again, a lining of callose, a $\beta-1,3-$ glucan polymer with $\beta-1,6$-branches, in the form of cell wall thickenings called papillae, synthesized from the sugar nucleotide UDP glucose through callose synthases (Flors et al., 2005) is required for efficient translocation of photoassimilates because it confers favorable flow characteristics on the pores (Barratt et al., 2011). Conversely, an increased deposition in the apoplast around sieve plate pores as happens in response to a range of biotic and abiotic stresses (Verma and Hong, 2001) may decrease the sieve pore diameter to the point of full occlusion as shown by ultraviolet fluorescence microscopy (Fig. 9). Although callose deposition was observed in both cases, the incidence of pluggings in sieve tube elements of afflicted vines was relatively higher than the healthy vines. So, the logical question to ask is why did both accumulate callose instead of just the afflicted vines? Given that grapevines naturally accumulate callose (dormancy) at the end of the season (Davis and Evert, 1970) and that all clusters were harvested just before harvest, the callose accumulation in healthy vines was most probably induced naturally by dormancy events during late in the ripening period as opposed to two events of callose accumulation, one an early induction by abiotic stimuli followed by accumulation of dormancy callose in SOUR shrivel berries. This is reflected in the composition of berries; the healthy berries had all desirable fruit quality attributes, whereas SOUR shrivel berries lacked such qualities.

It is known that both callose synthesis and $\mathrm{P}$ protein aggregation are $\mathrm{Ca}^{2+}$-dependent phenomena (Knoblauch et al., 2001) triggered by $\mathrm{Ca}^{2+}$ influx into sieve elements (Furch et al., 2010). Accordingly, the occlusion events of SOUR shrivel berries can be interpreted as some abiotic stress triggering influx of $\mathrm{Ca}^{2+}$ into sieve elements and occluding sieve plates by depositing callose in sieve pores. How any abiotic stress may trigger such an event is not clear. On the other hand, if the same phenomenon is induced by biotic stress, e.g., phytoplasma infection, $\mathrm{Ca}^{2+}$ outflows from wounded cell walls into sieve elements with concomitant gating of $\mathrm{Ca}^{2+}$-permeable channels leading to callose deposition and sieve plate occlusion (Musetti et al., 2013). Based on this observation, it is tempting to infer that callose is responsible for the incidence of SOUR shrivel through the impairment of mass flow, but even if this statement is made, it cannot be accepted uncritically because there is some flaw in this judgment of what is possible. Although callose deposition on sieve plates has been reported to reduce the rate of phloem translocation and can even block it completely (McNairn and Currier, 1967), autoradiographs showed no restriction in longitudinal movement of assimilates (Crafts and Crisp, 1971). This indicated that there is a degree of callose deposition in sieve plates, some accumulating more than the other, or it could be that callose plugging of sieve plates is pore size-dependent wherein small sieve plate pores might be occluded by callose, whereas large pores need additional mechanisms (Mullendore et al., 2010) involving a rapid occlusion by precipitating P proteins (Knoblauch and van Bel, 1998). It could also mean that phloem translocation operates by electro-osmosis, an alternative hypothesis developed to explain flow in phloem with plugged sieve plates (e.g., Siddiqui and Spanner, 1970), but was difficult to verify (Turgeon, 2010). The other likely scenario is the deposition of callose collars around the plasmodesmata of adjoining parenchyma cells blocking photoassimilate loading by sieve tubes. Furthermore, although callose is needed for the genesis of the sieve pores (Evert, 1990) and thus may be still present constitutively as collars around the sieve pores in intact sieve tubes (Ehlers et al., 2000) and the fact that a wide range of abiotic and biotic factors can certainly cause significant deposition of callose in mature sieve elements (Evert, 1982; Hughes and Gunning, 1980; Mullendore et al., 2010; Radford et al., 1998), a direct link between the callose deposition and phloem translocation is yet to be found in the literature.

Fruit COMPOSITION AND TISSUE INTEGRITY. A collapsed mesocarp would result in fruit of inferior quality attributable to a lack of competency of membranes without which sugar accumulation would not proceed as evident in SOUR shrivel berries (Table 1). Losses in membrane integrity occur when plants use vacuoles and vacuolar contents for PCD in response to biotic and abiotic stresses (Hara-Nishimura and Hatsugai, 2011). Failure in accumulating sugars would in turn affect synthesis of secondary metabolites such as anthocyanins (Dai et al., 2011), probably the first cues for frugivore (Rodriguez et al., 2013) and viticulturist attraction at distance and other phenolic compounds because these compounds are mostly synthesized in berries with sugars as the precursor molecules (Agasse et al., 2009). This explains deterioration of fruit quality attributes manifested as low contents of sugars, anthocyanin, and phenolic compounds (Table 2). Because both sugars and $\mathrm{K}$ are translocated in the phloem, the SOUR shrivel berries also had low $\mathrm{K}$ content (Table 1), which might have induced PCD because stress-induced leakage of $\mathrm{K}$ from plant cells is known to cause PCD (Demidchik et al., 2014). With regard to acids, the high amounts of tartaric acids (Table 2), which explains their low pH (Table 1) and low amounts of malic acid in SOUR shrivel berries compared with healthy berries, reflected stressinduced altered metabolism of acids. Although the precise role of tartaric acid is not clear (Conde et al., 2007), it could be that berries predisposed to SOUR shrivel synthesize an increased amount; hence, its heightened levels can be used as an index of berries experiencing abiotic stress. The low amount of malic acid was associated with their flaccidity (Bondada and Keller, 2012b), which would contribute to tonoplast leakage (DuPont, 1989) and eventually vacuolar decompartmentation of malate resulting changes in malic acid (Terrier et al., 2001). Other possible scenarios include reduced synthesis or high respiratory loss induced by stress. The high amounts of tannin in SOUR shrivel berries (Table 2) provide support for their 
stress-induced altered acid metabolism because tannins are known to increase in response to abiotic stress (Ramakrishna and Ravishankar, 2011). Now the logical question to put forward is whether sugar accumulation failed as a result of dead mesocarp cells through PCD in the presence of functional phloem or a lack of phloem functionality promoted cell death through PCD after veraison. These need to be examined in future studies by simulating SOUR shrivel in healthy vines. The healthy appearing berries of SOUR shrivel cluster however had better fruit composition but it was inferior to berries of healthy clusters (Table 1).

In conclusion, being sessile organisms, all plants alter structure and function to survive their challenging ecological niche. Accordingly, the structure-function framework that connects plants' performance with their cellular structure was applied to analyze the SOUR shrivel phenomenon for revealing cellular organizational disparities between healthy and vines afflicted with SOUR shrivel. The mesocarp in berries of SOUR shrivel was collapsed causing dramatic reductions in the amounts of sugars, anthocyanin, K, and malic acids, which paralleled with its lowest $\mathrm{pH}$. On the other hand, titratable acidity, tartaric acids, and tannins were much higher than healthy berries. Although the study provided several hints in the form of morphocytoarchitectural modifications such as an early activation of callose synthesis with subsequent plugging of sieve plates during ripening as a causative link to SOUR shrivel, the presence of such alterations in healthy vines, however, weakened their association with the disorder. Nevertheless, this comparison yielded an anatomically comprehensive atlas of clusters and stems pointing out phloem tissues for sourcing clues about what may be causing SOUR shrivel. Therefore, future studies should centralize temporal analysis of phloem structure to characterize spatial accumulation of callose and flows in sieve tube elements of phloem-girdled grapevines simulating SOUR shrivel clusters toward its mechanistic understanding.

\section{Literature Cited}

Agasse, A., C. Vignault, C. Kappel, C. Conde, H. Geros, and S. Delrot. 2009. Sugar transport and sugar sensing in grape, p. 105-128. In: Roubelakis-Angelakis, K.A. (ed.). Grapevine molecular physiology and biotechnology. Springer, New York, NY.

Agusti, M., V. Almela, M. Juan, F. Alferez, F.R. Tadeo, and L. Zazariaas. 2001. Histological and physiological characterization of rind breakdown of 'Navelate' sweet orange. Ann. Bot. (Lond.) 88:415-422.

Bachteler, K., M. Riedel, N. Merkt, B. Ulrich, M. Erhardt, and J. Wunsche. 2013. Effect of soil fertilization on the incidence of berry shrivel and the quality of resulting wine. Vitis 52:1-7.

Barratt, D.H.P., K. Kolling, A. Graf, P. Marilyn, G. Calder, K. Findlay, S.C. Zeeman, and A.M. Smith. 2011. Callose synthase GSL7 is necessary for normal phloem transport and inflorescence growth in Arabidopsis. Plant Physiol. 155:328-341.

Bioletti, F. 1923. Blackmeasles, waterberries and related troubles. California Agr. Expt. Sta. Bul. 358.

Bonada, M., V.O. Sadras, and S. Fuentes. 2013. Effect of elevated temperature on the onset and rate of mesocarp cell death in berries of Shiraz and Chardonnay and its relationship with berry shrivel. Austral. J. Grape Wine Res. 19:87-94.

Bondada, B. 2012. Technical advance: Novel, simple, fast, and safe approaches to visualizing fine cellular structures in free-hand sections of stem, leaf, and fruit using optical microscopy. Curr. Bot. 3:11-22. Bondada, B. and M. Keller. 2012a. Not all shrivels are created equal-Morpho-anatomical and compositional characteristics vary among different shrivel forms that develop during ripening of grape (Vitis vinifera) berries. Amer. J. Plant Sci. 3:879-898.

Bondada, B. and M. Keller. 2012b. Morpho-anatomical symptomatology and osmotic behavior of grape berry shrivel. J. Amer. Soc. Hort. Sci. 137:20-30.

Bondada, B.R., M. Keller, and G. Hall. 2009. Compositional and anatomical characterization of SOUR berry. Proc. Intl. Viticult. Symp. 16:157-159.

Bouzayen, M., A. Latche, P. Nath, and J.C. Pech. 2010. Mechanism of fruit ripening, p. 319-339. In: Eng, P.E. and M.R. Davey (eds.). Plant developmental biology-Biotechnological perspectives. Vol. 1. Springer-Verlag, Berlin/Heidelberg, Germany.

Brodersen, C., B. Choat, D. Chatelet, K. Shackel, M.A. Matthews, and A. McElrone. 2013. Xylem vessel relays contribute to radial connectivity in grapevine stems (Vitis vinifera and $V$. arizonica; Vitaceae). Amer. J. Bot. 100:314-321.

Carlquist, S. 1975. Ecological strategies of xylem evolution. Univ. California Press, Berkeley, CA.

Carlquist, S. 1984. Vessel grouping in dicotyledon woods: Significance and relationship to imperforate tracheary elements. Aliso 10:505-525.

Carlquist, S. 1991. Anatomy of vines and liana stems: A review and synthesis, p. 53-71. In: Putz, F.E. and H.A. Mooney (eds.). The biology of vines. Cambridge Univ. Press, Cambridge, UK.

Carlquist, S. 2001. Comparative wood anatomy. 2nd Ed. SpringerVerlag, Berlin/Heidelberg, Germany.

Ceponis, M.J., R.A. Cappellini, J.M. Wells, and G.W. Lightner. 1987. Disorders in plum, peach, and nectarine shipments to the New York market, 1972-1985. Plant Dis. 71:947-952.

Chatelet, D.S., M.A. Matthews, and T.L. Rost. 2006. Xylem structure and connectivity in grapevine (Vitis vinifera) shoots provides a passive mechanism for the spread of bacteria in grape plants. Ann. Bot. (Lond.) 98:483-494.

Choat, B., A.R. Cobb, and S. Jansen. 2008. Structure and function of bordered pits: New discoveries and impacts on whole plant hydraulic function. New Phytol. 177:608-625.

Conde, C., P. Silva, N. Fontes, A.C.P. Dias, R.M. Tavares, M.J. Sousa, A. Agasse, S. Delrot, and H. Gerós. 2007. Biochemical changes throughout grape berry development and fruit and wine quality. Food $1: 1-22$.

Coombe, B.G. 1992. Research on development and ripening of the grape berry. Amer. J. Enol. Viticult. 43:101-110.

Crafts, A.S. and C.E. Crisp. 1971. Phloem transport in plants. Freeman, San Francisco, CA.

Dai, Z.W., N. Ollat, E. Gomes, S. Decroocq, J.P. Tandonnet, L. Bordenave, P. Pieri, G. Hilbert, C. Kappel, C.V. Leeuwen, P. Vivin, and S. Delrot. 2011. Ecophysiological, genetic, and molecular causes of variation in grape berry weight and composition: A review. Amer. J. Enol. Viticult. 62:413-425.

Davis, J.D. and R.F. Evert. 1970. Seasonal cycle of phloem development in woody vines. Bot. Gaz. 131:128-138.

Demidchik, V., D. Straltsova, S.S. Medvedev, G.A. Pozhvanov, A. Sokolik, and V. Yurin. 2014. Stress-induced electrolyte leakage: The role of $\mathrm{K}+$-permeable channels and involvement in programmed cell death and metabolic adjustment. J. Expt. Bot. 65:1259-1270.

Diggle, P.K. 1995. Architectural effects and the interpretation of patterns of fruit and seed development. Annu. Rev. Ecol. Syst. 26:531-552.

Dudley, R. 2004. Ethanol, fruit ripening, and historical origins of human alcoholism in primate frugivory. Integr. Comp. Biol. 44:315323.

DuPont, F.M. 1989. Effect of temperature on the plasma membrane and tonoplast ATPase of barley roots. Plant Physiol. 89:1401-1412.

Ehlers, K., M. Knoblauch, and A.J.E. van Bel. 2000. Ultrastructural features of well-preserved and injured sieve elements: Minute clamps keep the phloem transport conduits free for mass flow. Protoplasma 214:80-92. 
Esau, K. 1965. Vascular differentiation in plants. Holt Rinehart Winston, New York, NY.

Evert, R.F. 1982. Sieve-tube structure in relation to function. Bioscience 32:789-795.

Evert, R.F. 1990. Dicotyledons, p. 103-137. In: Behnke, H.D. and R.D. Sjolund (eds.). Sieve elements: Comparative structure, induction and development. Springer-Verlag, Berlin/Heidelberg, Germany.

Flors, V., J. Ton, G. Jakab, and B. Mauch-Mani. 2005. Abscisic acid and callose: Team players in defense against pathogens? J. Phytopathol. 153:377-383.

Freeman, B. 1976. Rind blemish of citrus. II. Structure and ultrastructure. Sci. Hort. 4:329-336.

Fuentes, S., W. Sullivan, J. Tilbrook, and S. Tyerman. 2010. A novel analysis of grapevine berry tissue demonstrates a variety dependent correlation between tissue vitality and berry shrivel. Austral. J. Grape Wine Res. 16:327-336.

Fukuda, H. 2000. Programmed cell death of tracheary elements as a paradigm in plants. Plant Mol. Biol. 44:245-253.

Furch, A.C.U., M.R. Zimmermann, T. Will, J.B. Hafke, and A.J.E. van Bel. 2010. Remote-controlled stop of mass flow by biphasic occlusion in Cucurbita maxima. J. Expt. Bot. 61:3697-3708.

Giovannoni, J.J. 2007. Fruit ripening mutants yield insights into ripening control. Curr. Opin. Plant Biol. 10:283-289.

Greenberg, J.T. 1996. Programmed cell death: A way of life for plants. Proc. Natl. Acad. Sci. USA 93:12094-12097.

Griesser, M., R. Eder, S. Besser, and A. Forneck. 2012. Berry shrivel of grapes in Austria-Aspects of the physiological disorder with cultivar Zweigelt (Vitis vinfera L.). Sci. Hort. 145:87-93.

Guichard, S., N. Bertin, C. Leonard, and C. Gary. 2001. Tomato fruit quality in relation to water and carbon fluxes. Agronomie 21:385392.

Hall, G., B.R. Bondada, and M. Keller. 2011. Loss of rachis cell viability is associated with ripening disorders in grapes. J. Expt. Bot. 62:1145-1153.

Hara-Nishimura, I. and N. Hatsugai. 2011. The role of vacuole in plant cell death. Cell Death Differ. 18:1298-1304.

Harris, N.N., J.M. Luczo, S.P. Robinson, and A.R. Walker. 2013. Transcriptional regulation of the three grapevine chalcone synthase genes and their role in flavonoid synthesis in Shiraz. Austral. J. Grape Wine Res. 19:221-229.

Ho, Q.T., P. Verboven, B.E. Verlinden, and B.M. Nicola1. 2010. A model for gas transport in pear fruit at multiple scales. J. Expt. Bot. 61:2071-2081.

Hughes, J.E. and B.E.S. Gunning. 1980. Glutaraldehyde-induced deposition of callose. Can. J. Bot. Rev. 58:250-258.

Hughes, N.M. 2011. Leaf reddening in 'evergreen' species. New Phytol. 190:573-581.

Jeong, S.T., N. Goto-Yamamoto, K. Hashizume, S. Kobayashi, and M. Esaka. 2006. Expression of $V v m y b A l$ gene and anthocyanin accumulation in various grape organs. Amer. J. Enol. Viticult. 57:507510.

Jones, C.S. and M.A. Watson. 2001. Heteroblasty and preformation in mayapple, Podophyllum peltatum (Berberidaceae): Developmental flexibility and morphological constraint. Amer. J. Bot. 88:1340 1358.

Jones, G.V., A.A. Duff, A. Hall, and J.W. Myers. 2010. Spatial analysis of climate in 558 winegrape growing regions in the western United States. Amer. J. Enol. Viticult. 61:313-326.

Kader, A.A. 1999. Fruit maturity, ripening and quality relationships. Acta Hort. 485:203-208.

Knoblauch, M. and W. Peters. 2010. Münch, morphology, microfluidics-Our structural problem with the phloem. Plant Cell Environ. 33:1439-1452.

Knoblauch, M., W.S. Peters, K. Ehlers, and A.J.E. van Bel. 2001. Reversible calcium-regulated stopcocks in legume sieve tubes. Plant Cell 13:1221-1230.

Knoblauch, M. and A.J.E. van Bel. 1998. Sieve tubes in action. Plant Cell 10:35-50.
Knoll, M., D. Achleitner, and H. Redl. 2010. Sugar accumulation in 'Zweigelt' grapes as affected by 'Traubenwelke'. Vitis 49:101-106. Krasnow, M., N. Weis, R.J. Smith, M.J. Benz, M.A. Matthews, and K.A. Shackel. 2009. Inception, progression, and compositional consequences of a berry shrivel disorder. Amer. J. Enol. Viticult. 60:24-34.

Krasnow, M.N., M.A. Matthews, and K. Shackel. 2008. Evidence for substantial maintenance of membrane integrity and cell viability in normally developing grape (Vitis vinifera) berries throughout development. J. Expt. Bot. 59:849-859.

Krasnow, M.N., M.A. Matthews, R.J. Smith, J. Benz, E. Weber, and K.A. Shackel. 2010. Distinctive symptoms differentiate four common types of berry shrivel disorder in grape. Calif. Agr. 64:155-159

Lev-Yadun, S., M. Inbar, I. Izhaki, and G. Neemen. 2002. Color patterns in vegetative parts of plants deserve more attention. Trends Plant Sci. 7:59-60.

Liakopoulos, G., D. Nikolopoulos, A. Klouvatoui, V. KorniliosAndrianos, Y. Manetas, and G. Karabourniotis. 2006. The photoprotective role of epidermal anthocyanins and surface pubescence in young leaves of grapevine (Vitis vinifera). Ann. Bot. (Lond.) 98:257265.

McNairn, R.B. and H.B. Currier. 1967. Sieve plate callose: A factor in blockage of axial phloem transport. Naturwissenschaften 54:591.

Miqueloto, A., C.V.T. Cristiano, A. Steffens, A. Santos, and E. Mitcham. 2014. Relationship between xylem functionality, calcium content and the incidence of bitter pit in apple fruit. Sci. Hort. 165:319-323.

Mullendore, D.L., C.W. Windt, H.V. As, and M. Knoblauch. 2010. Sieve tube geometry in relation to phloem flow. Plant Cell 22:579-593.

Musetti, R., S.V. Buxa, F. De Marco, A. Loschi, R. Polizzotto, K.H. Kogel, and A.J.E. van Bel. 2013. Phytoplasma-triggered $\mathrm{Ca}^{2+}$ influx is involved in sieve-tube blockage. Mol. Plant Microbe Interact. 26:379-386.

Nozzolilo, C. 1979. On the role of anthocyanins in vegetative tissues: A relationship with stem length in pea seedlings. Can. J. Bot. 57:2554-2558.

Oda, Y. and H. Fukuda. 2012. Secondary cell wall patterning during xylem differentiation. Curr. Opin. Plant Biol. 15:38-44.

Pratt, C. 1971. Reproductive anatomy of cultivated grapes-A review. Amer. J. Enol. Viticult. 22:92-109.

Radford, J., M. Vesk, and R. Overall. 1998. Callose deposition at plasmodesmata. Protoplasma 201:30-37.

Ramakrishna, A. and G.A. Ravishankar. 2011. Influence of abiotic stress signals on secondary metabolites in plants. Plant Signal. Behav. 6:1720-1731.

Ribéreau-Gayon, P., Y. Glories, A. Maujean, and D. Dubourdieu. 2000. Varietal aroma, p. 187-206. In: Ribéreau-Gayon, P., Y. Glories, A. Maujean, and D. Dubourdieu (eds.). The chemistry of wine stabilization and treatments: Handbook of enology. Vol. II. Wiley, Hoboken, NJ.

Rodriguez, A., B. Alquezar, and L. Pena. 2013. Fruit aromas in mature fleshy fruits as signals of readiness for predation and seed dispersal. New Phytol. 197:36-48.

Rogiers, S.Y., J.M. Hatfield, V.G. Jaudzems, R.G. White, and M. Keller. 2004. Grape berry cv. Shiraz epicuticular wax and transpiration during ripening and preharvest weight loss. Amer. J. Enol. Viticult. 55:121-127.

Ruzin, S.E. 1999. Plant microtechnique and microscopy. Oxford Univ. Press, New York, NY.

Siddiqui, A.W. and D.C. Spanner. 1970. The state of the pores in functioning sieve plates. Planta 91:181-189.

Singh, R., R.R. Sharma, and S.K. Tyagi. 2007. Pre-harvest foliar application of calcium and boron influences physiological disorders, fruit yield and quality of strawberry (Fragaria $\times$ ananassa Duch.). Sci. Hort. 112:215-220.

Sperry, J.S. and U.G. Hacke. 2004. Analysis of circular bordered pit function I. Angiosperm vessels with homogeneous pit membranes. Amer. J. Bot. 91:369-385. 
Stevenson, J.F., M.A. Matthews, and T.L. Rost. 2005. The developmental anatomy of Pierce's disease symptoms in grapevines: Green islands and matchsticks. Plant Dis. 89:543-548.

Sun, Q., L.C. Greve, and J.M. Labavitch. 2011. Polysaccharide compositions of intervessel pit membranes contribute to Pierce's disease resistance of grapevines. Plant Physiol. 155:1976-1987.

Terrier, N., F.X. Sauvage, A. Ageorges, and C. Romieu. 2001. Changes in acidity and in proton transport at the tonoplast of grape berries during development. Planta 1:20-28.

This, P., T. Lacombe, and M.R. Thomas. 2006. Historical origins and genetic diversity of wine grapes. Trends Genet. 22:511-519.

Tilbrook, J. and S.D. Tyerman. 2008. Cell death in grape berries: Varietal differences linked to xylem pressure and berry weight loss. Funct. Plant Biol. 35:173-184.

Turgeon, R. 2010. The puzzle of phloem pressure. Plant Physiol. 154:578-581.
Vaillant-Gaveau, N., P. Maillard, G. Wojnarowiez, P. Gross, C. Clement, and F. Fontaine. 2011. Inflorescence of grapevine (Vitis vinifera): A high ability to distribute its own assimilates. J. Expt. Bot 62:4183-4190.

Wang, H., W. Wang, H. Li, P. Zhang, J. Zhan, and W. Huang. 2011. Expression and tissue and subcellular localization of anthocyanidin synthase (ANS) in grapevine. Protoplasma 248:267-279.

Watkins, C.B. 2007. The effect of 1-MCP on the development of physiological storage disorders in horticultural crops. Stewart Postharvest Rev. 2:1-6.

Wilson, A.L. and C.T. Downs. 2012. Fruit nutritional composition and non-nutritive traits of indigenous South African tree species. S. Afr. J. Bot. 78:30-36.

Zimmermann, M.H. 1978. Hydraulic architecture of some diffuseporous tress. Can. J. Bot. 56:2287-2295.

Verma, D.P.S. and Z. Hong. 2001. Plant callose synthase complexes. Plant Mol. Biol. 47:693-701. 